\title{
Intractable Epilepsy
}

National Cancer Institute

\section{Source}

National Cancer Institute. Intractable Epilepsy. NCI Thesaurus. Code C9487.

Epilepsy that is refractory to treatment. 